\title{
The association between periodontal disease and adverse pregnancy outcomes in Northern Tanzania: a cross-sectional study
}

\author{
Nyobasi Gesase ${ }^{1}$, Jaume Miranda-Rius ${ }^{2,3}$, Lluís Brunet-Llobet ${ }^{3,4}$, Eduard Lahor-Soler ${ }^{2,3}$, \\ Michael J Mahande ${ }^{5}$, Gileard Masenga ${ }^{1}$
}

1. Department of Obstetrics and Gynaecology, Kilimanjaro Christian Medical Centre (KCMC)/Kilimanjaro Christian Medical University College (KCMU College), Moshi, Tanzania.

2. Department of Odontostomatology. Faculty of Medicine and Health Sciences. Universitat de Barcelona, Barcelona, Spain.

3. Hospital Dentistry \& Periodontal Medicine Research Group, Institut de Recerca Sant Joan de Déu (IRSJD), Fundació Sant Joan de Déu, Barcelona, Spain.

4. Division of Pediatric Dentistry. Hospital Universitari Sant Joan de Déu. Universitat de Barcelona, Barcelona, Spain.

5. Department of Epidemiology and Biostatistics. Institute of Public Health. Kilimanjaro Christian Medical University College (KCMU College), Moshi, Tanzania.

\begin{abstract} delivering at the Kilimanjaro Christian Medical Centre (KCMC). assess periodontal disease developing countries. disease; periodontitis; cross-sectional studies.

DOI: https://dx.doi.org/10.4314/ahs.v18i3.18 ahs.v18i3.18

\section{Corresponding author: \\ Jaume Miranda-Rius \\ Department of Odontostomatology, \\ Faculty of Medicine and Health Sciences \\ University of Barcelona \\ Feixa Llarga, s/n, 08907 L'Hospitalet de Llobregat, \\ Barcelona, Catalonia, Spain \\ Tel: +34 934024269 Fax: +34 934035558 \\ e-mail: jmiranda-rius@ub.edu}

Background: For the past two decades, studies have investigated the relationship between periodontal disease and adverse pregnancy outcomes such as pre-eclampsia, preterm birth, low birth weight and preterm premature rupture of membranes.

Objectives: To determine the prevalence of periodontal disease and associated adverse pregnancy outcomes among women

Methods: This cross-sectional study was based on the use of patients' files, clinical examinations and oral interviews with mothers who delivered at the KCMC. Pregnant women with singleton babies $(\mathrm{N}=1117)$ who delivered at the KCMC were recruited for the study. Intra-oral examination was performed within five days of birth. The Community Periodontal Index was used to

Results: The prevalence of periodontal disease was $14.2 \%$. Periodontal disease was significantly associated with higher odds of pre-eclampsia [adjusted Odds Ratio 95\% Confidence Interval (aOR=4.12;95\%CI:2.20-7.90)], low birth weight $(\mathrm{aOR}=2.41 ; 95 \%$ CI:1.34-4.33) and preterm birth ( $\mathrm{aOR}=2.32 ; 95 \% \mathrm{CI}: 1.33-4.27)$. There was no significant association between periodontal disease and preterm premature rupture of membranes (aORs 1.83;95\%CI:0.75-4.21) and eclampsia (3.71;95\%CI:0.80-17.13).

Conclusion: Maternal periodontal disease is a potential independent risk indicator for pre-eclampsia, low birth weight, and preterm birth. Periodontal assessment and therapy should form part of the preventive antenatal care provided to women in

Keywords: Preterm birth; low birth weight; pre-eclampsia; eclampsia; preterm premature rupture of membranes; periodontal

Cite as: Gesase N, Miranda-Rius J, Brunet-Llobet L, Labor-Soler E, Mahande MJ, Masenga G. The association between periodontal disease and adverse pregnancy outcomes in Northern Tanzania: a cross-sectional study. Afri Health Sci. 2018;18(3): 601-611. bttps:/ / dx.doi.org/10.4314/

\section{Introduction}

Adverse pregnancy outcomes such as pre-eclampsia (PE), eclampsia, preterm premature rupture of membranes (pPROM), preterm birth (PTB) and low birth weight (LBW) are all associated with maternal and neonatal morbidity and mortality. These outcomes also represent a serious public health problem. Maternal periodontal disease can adversely affect pregnancy, by causing bacteria and inflammatory mediators to spread from the oral cavity to the fetal placental unit via the blood ${ }^{1}$.

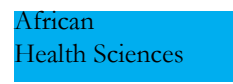

(C) 2018 Gesase et al. Licensee African Health Sciences. This is an Open Access article distributed under the terms of the Creative commons Attribution License (https://creativecommons.org/licenses/BY/4.0), which permits unrestricted use, distribution, and reproduction in any medium, provided the original work is properly cited. 
The American Academy of Periodontology defines periodontal disease as an inflammatory disease that affects the soft and hard structures supporting the teeth ${ }^{2}$. In the early stage of the disease, which is known as gingivitis, the gums become swollen and red due to inflammation, which is the body's natural response to the presence of harmful bacteria. In the more serious form of periodontal disease, called periodontitis, the gums pull away from the tooth and the supporting gum tissues are destroyed ${ }^{2}$. Periodontitis is principally caused by Gram-negative anaerobic bacteria, which raise local and systemic levels of pro-inflammatory mediators ${ }^{3}$.

The prevalence of periodontal disease varies depending on the population studied and the definition used. For example, in industrialized areas it affects between 20\% and $50 \%$ of pregnant women ${ }^{4,5}$. The World Bank Country classification defines the United Republic of Tanzania as a low-income economy ${ }^{6}$. A systematic review and meta regression of the global burden of severe periodontitis calculated its prevalence in Tanzania to be $20 \% 7$. In Africa, and specifically in Tanzania, data on periodontal health in pregnancy are limited. However, one study in a rural population in Uganda reported 67\% prevalence of periodontal disease among pregnant women ${ }^{8}$.

At the 1996 World Workshop in Periodontics, the term "periodontal medicine" was introduced to define a discipline focused on the evaluation of the two-way relationship between the fields. Periodontal disease can have a major impact on individual systemic health, and in turn systemic diseases may influence periodontal health as well ${ }^{9}$.

Gingivitis and periodontitis usually involve active chronic infections which may increase the risk of adverse pregnancy outcomes such as PTB, LBW, pPROM and PE. The presence of a large ulcerated epithelium surface in periodontal pockets allows bacteria and their products to reach other parts of the body, causing lesions at different levels. Certain bacteria such as Porphyromona gingivalis and Aggregatibacter actinomycetemcomitans may even invade cells and tissues directly ${ }^{10-12}$. Periodontal bacteria in pregnant women with periodontitis may induce the cascade of immuno-inflammatory mediators such as PGE2, IL-6, IL-1, and TNF- $\alpha$ which may be implicated in adverse pregnancy outcomes ${ }^{4,13}$.
In periodontitis, periodontal pathogens or by-products may reach the placenta and spread to the fetal circulation and amniotic fluid. Their presence in the fetal-placental compartment can stimulate a fetal immune/inflammatory response characterized by the production of $\operatorname{IgM}$ antibodies against the pathogens and the secretion of elevated levels of inflammatory mediators, which in turn may cause miscarriage or premature birth. Moreover, infection/inflammation may cause placental structural changes leading to pre-eclampsia and impaired nutrient support, thus reducing birth weight. Fetal exposure may also result in tissue damage and increase the risk of perinatal morbidity and mortality ${ }^{14}$.

The international definition of low birth weight is a weight "below 2500g" regardless of gestational age. Weights below $1500 \mathrm{~g}$ are considered very low (VLBW) and weights below $1000 \mathrm{~g}$ as extremely low (ELBW) ${ }^{15}$. In Tanzania, a birth weight less than $1000 \mathrm{~g}$ is considered as an abortion, as the fetus is non-viable.

Preterm or premature birth (PTB) is usually defined as a gestational age of less than 37 completed weeks. Preterm premature rupture of membranes ( $\mathrm{PPROM}$ ) is defined as rupture of the fetal membranes before the onset of labour and prior to 37 weeks of gestation ${ }^{10}$. From the epidemiological perspective, the incidence of PTB reported in the literature varies, because it is a multifactorial problem influenced by geographical and socio-economic factors, racial characteristics, age, and quality of prenatal care. PTB occurs in approximately $8-10 \%$ of pregnancies in developed countries but this figure may be as high as $43 \%$ in parts of the developing world. Unfortunately, preterm birth and low birth weight rates are also high elsewhere: Europe 4 to $12 \%$, Asia 15\%, Africa 10 to $12 \%$, Australia 6\% and North America 7\% ${ }^{16}$.

Pre-eclampsia is a multi-factorial inflammatory disorder that is a major cause of maternal and perinatal morbidity and mortality. The syndrome is characterised by inappropriate inflammatory and abnormal vascular response to placentation which causes endothelial dysfunction, resulting in maternal hypertension during pregnancy ${ }^{3}$.

Several studies have explored the relationship between periodontal health status and adverse pregnancy outcomes such as PTB, LBW, PE and pPROM. However most of these studies have focused almost exclusively on 
PTB and LBW in relation to systemic maternal infections. The aim of our study was to determine the prevalence of periodontal disease among pregnant women in Northern Tanzania, and to analyse its possible association with these adverse pregnancy outcomes.

\section{Methods \\ Study design}

We performed a cross-sectional study of all pregnant women delivering at the Kilimanjaro Christian Medical Center (KCMC) in Moshi, Northern Tanzania,between September 2015 and April 2016. The KCMC is a zonal consultant and university teaching hospital serving the local community and referred cases from six regions in Northern Tanzania. These include Kilimanjaro, Arusha, Manyara, Tanga, Singida and Dodoma with approximately 15 million inhabitants. The Department of Obstetrics and Gynaecology (KCMC Birth Medical Registry 2012) provides birth care services to pregnant women from the nearby communities as well as referral cases from other regions. It has an average of 3,300 deliveries per year.

\section{Study subjects}

This study included all pregnant women $(n=1117)$ delivering at the KCMC labour ward, aged from 18 to 46 years, with singleton intrauterine fetuses of a gestational age between 28 and 42 weeks. Multiple gestations, women with any systemic infection apart from periodontitis, and those who lacked the number of teeth necessary to register the Community Periodontal Index (CPI) were excluded. Study participants were recruited at the time of admission to the labour and delivery area ${ }^{17,18}$. They all provided signed consent and their information was gathered together using a structured questionnaire, where their sociodemographic characteristics, previous obstetric history and the index pregnancy information were recorded.

Periodontal examination was performed within five days of delivery by the same obstetrician (NG), who had received training in oral examination from a senior researcher in periodontics (JMR). The intraexaminer calibration was followed by assessments of the clinician's ability over a three-month period prior to the start of the study ${ }^{19}$.

Clinical periodontal examination was done using the epidemiological section of the Community Periodontal Index of Treatment Needs known as the Community Periodontal Index $(\mathrm{CPI})^{17}$. In each participant, ten teeth were assessed $(17,16,11,26,27,47,46,31,36,37)$ using a standard periodontal probe (Michigan 8/11, Hu-Friedy, and Chicago, IL, USA). The probing depth involved three measurements in mesial-medial-distal for buccal surfaces and lingual-palatal surfaces respectively. The CPI scoring criteria were defined as follows: $0=$ no periodontal disease; 1 = bleeding on probing; probing depth $\leq 3 \mathrm{~mm}$; 2 $=$ calculus with plaque seen or felt by probing; $3=$ pathological pocket $>3 \mathrm{~mm}$ and $<6 \mathrm{~mm}$, and $4=$ pathological pocket $\geq 6 \mathrm{~mm}$; thus, a score of 0 meant no periodontal disease, 1 - 2 gingivitis and 3 - 4 periodontitis. Assessment of gingival recession included only one measurement in medial for buccal and lingual-palatal surfaces ${ }^{20}$. Dental mobility was classified as grade I, II, or III. Other parameters such as gingival enlargement ${ }^{21}$, were also considered.

\section{Measurements}

In this study the outcome variables were pPROM, PE/ eclampsia, PTB and LBW, while periodontal disease (PD) was the main exposure of interest. Other variables such as age, marital status, level of education, height, weight, body mass index, cigarette smoking, alcohol consumption, previous history of pPROM, LBW, PE, PTB, HIV status, urinalysis, VDRL, blood group and Rh factor, haemoglobin level, blood slide for malaria parasite/malaria rapid diagnostic test gestation age at delivery, birth weight, mode of delivery, number of teeth, and tooth mobility were also assessed as co-variates.

\section{Statistical analysis}

Data were analysed using SPSS version 20. Descriptive statistics were summarized using mean and SD for continuous variables while frequency and proportions were used for categorical variables. Odds ratios (OR) with 95\% Confidence Intervals (CI) for the adverse pregnant outcomes associated with periodontal disease were estimated using a multivariable logistic model. A $p$-value of less than 0.05 (2-tailed) was considered statistically significant.

\section{Results}

A total of 1,117 participants were eligible and were enrolled in the study. Their demographic characteristics are shown in Table 1 . Mean age was 28.5 years (SD \pm $5.9), 568(50.9 \%)$ were aged between 26 and 35 years, 435 $(38.9 \%)$ attained post-secondary school education, and 1005 (90\%) were married. The vast majority 967 (86.6\%) were between parity 1 and parity 3, 150 (13.4\%) had par- 
ity $>3$, and mean parity was $2(\mathrm{SD} \pm 1)$. One thousand and four $(89.9 \%)$ had between one and three living children; $63.1 \%$ gave birth via vaginal delivery, $35.3 \%$ by cesarean section, $1.1 \%$ by vacuum and $0.5 \%$ by assisted breech. Mean gestation age at birth was 39.0 weeks (SD $\pm 2.3,28.0-44.0)$, with preterm delivery accounting for $9.8 \%(\mathrm{n}=110) ; 897(80.3 \%)$ were term deliveries, and 110 (9.8\%) were post-term; $123(11.0 \%)$ were LBW, 84.2\% were normal birth weight $(>2.5 \mathrm{~kg}$ to $<4 \mathrm{~kg})$ and $4.7 \%$ were overweight $(>4 \mathrm{~kg})$.

Table 1: Characteristics of study participants $(\mathrm{N}=1117)$

\begin{tabular}{|c|c|c|}
\hline Variable & $\mathrm{n}$ & $(\%)$ \\
\hline \multicolumn{3}{|l|}{ Age (years): } \\
\hline $18-25$ & 383 & (34.3) \\
\hline $26-35$ & 568 & (50.9) \\
\hline $36-46$ & 166 & (14.9) \\
\hline Mean ( $\pm S D)$ & 28.5 & $( \pm 5.9)$ \\
\hline \multicolumn{3}{|l|}{ Level of education: } \\
\hline No formal education & 15 & $(1.3)$ \\
\hline Primary & 416 & $(37.2)$ \\
\hline Secondary & 251 & $(22.5)$ \\
\hline Post-secondary & 435 & (38.9) \\
\hline \multicolumn{3}{|l|}{ Marital status: } \\
\hline Never married & 112 & $(10.0)$ \\
\hline Ever married & 1005 & $(90.0)$ \\
\hline \multicolumn{3}{|l|}{ Parity: } \\
\hline $1-3$ & 967 & (86.6) \\
\hline More than 3 & 150 & (13.4) \\
\hline Mean ( $($ SD) & 2 & $( \pm 1)$ \\
\hline \multicolumn{3}{|c|}{ Number of living children: } \\
\hline $1-3$ & 1004 & (89.9) \\
\hline More than 3 & 113 & (10.1) \\
\hline Mean ( $\pm S D)$ & 2 & $( \pm 1,0-11)$ \\
\hline \multicolumn{3}{|c|}{ Body Mass Index $(\mathrm{kg} / \mathrm{m} 2)$ : } \\
\hline Underweight & 43 & $(3.8)$ \\
\hline Normal & 605 & $(54.2)$ \\
\hline Overweight & 320 & $(28.6)$ \\
\hline Obese & 149 & (13.3) \\
\hline Mean ( $($ SD) & 24.9 & $( \pm 4.4)$ \\
\hline \multicolumn{3}{|l|}{ Blood pressure $(\mathrm{mmHg})$ : } \\
\hline Normal & 1014 & $(90.8)$ \\
\hline High & 103 & $(9.2)$ \\
\hline \multicolumn{3}{|c|}{ First antenatal visit (weeks) $(n=1110)$ : } \\
\hline Up to 14 & 281 & $(25.3)$ \\
\hline More than 14 & 829 & (74.7) \\
\hline Mean ( $\pm S D)$ & 17.9 & $( \pm 5.3)$ \\
\hline \multicolumn{3}{|l|}{ Mode of delivery: } \\
\hline Spontaneous vaginal & 705 & $(63.1)$ \\
\hline Caesarian section & 394 & (35.3) \\
\hline Vacuum extraction & 12 & $(1.1)$ \\
\hline Assisted breach & 6 & $(0.5)$ \\
\hline \multicolumn{3}{|l|}{ Alcohol consumption: } \\
\hline Yes & 208 & $(18.6)$ \\
\hline No & 909 & $(81.4)$ \\
\hline
\end{tabular}


The prevalence of periodontal disease was $14.2 \%$ $(\mathrm{n}=159)$; however, severe periodontitis (grade 4) was found in only $5.0 \%$ of this group. The characteristics of study participants and the presence of periodontal disease are shown in Table 2.

With reference to the distribution of periodontal disease, adjusted for the age of the sample, women aged 36 to 46 years had a 2.1-times higher odds of periodontal disease
[Odds Ratio 95\% Confidence Interval (OR $=2.1 ; 95 \%$ CI: 1.30-3.40)] compared with the youngest group (18 to 25 years). When parity was compared, the odds of having periodontal disease in the $1-3$ parity group was half that recorded in women with higher parity $(\mathrm{OR}=0.5 ; 95 \%$ CI: 0.30-0.70). Other variables such as level of education, marital status, HIV status, body mass index and alcohol consumption did not influence the occurrence of periodontal disease (Table 2).

Table 2: Characteristics of postpartum mothers and presence of periodontal disease $(n=1117)$

\begin{tabular}{|c|c|c|c|c|c|}
\hline \multirow{3}{*}{ Variable } & \multirow{3}{*}{ Total } & \multicolumn{2}{|c|}{$\begin{array}{c}\text { Presence of periodontal } \\
\text { disease }\end{array}$} & \multirow{3}{*}{ OR $(95 \% \mathrm{Cl})$} & \multirow{3}{*}{$p$-value } \\
\hline & & \multirow{2}{*}{$\begin{array}{c}\text { Present } \\
n \quad(\%)\end{array}$} & \multirow{2}{*}{$\begin{array}{c}\text { Absent } \\
n(\%) \\
\end{array}$} & & \\
\hline & & & & & \\
\hline Age (years): & & & & MD (95\% Cl) & \\
\hline Mean (SD) & & $30.0(6.6)$ & $28.2(5.7)$ & $1.8(0.8-2.7)$ & 0.001 \\
\hline $18-25$ & 383 & $50(13.1)$ & $333(86.9)$ & 1.0 & \\
\hline $26-35$ & 568 & $69(12.1)$ & $499(87.9)$ & $0.9(0.6-1.4)$ & 0.679 \\
\hline $36-46$ & 168 & $40(24.1)$ & $126(75.9)$ & $2.1(1.3-3.4)$ & 0.001 \\
\hline \multicolumn{6}{|l|}{ Level of education: } \\
\hline No formal education & 15 & $4(26.7)$ & $11(73.3)$ & 1.0 & \\
\hline Primary & 416 & $74(17.8)$ & $342(82.2)$ & $0.6(0.2-1.9)$ & $0.491^{*}$ \\
\hline Secondary & 251 & $34(13.5)$ & $217(86.5)$ & $0.4(0.1-1.4)$ & $0.243^{*}$ \\
\hline Post-secondary & 435 & $47(10.8)$ & $388(89.2)$ & $0.3(0.1-1.1)$ & $0.078^{*}$ \\
\hline \multicolumn{6}{|l|}{ Marital status: } \\
\hline Never married & 112 & $13(11.6)$ & $99(88.4)$ & & \\
\hline $\begin{array}{l}\text { Ever married } \\
\text { Body mass index } \\
\text { (kg/m2): }\end{array}$ & 1005 & $146(14.5)$ & $859(85.5)$ & $0.8(0.4-1.4)$ & 0.401 \\
\hline Underweight & 43 & $6(14.0)$ & $37(86.0)$ & 1.0 & \\
\hline Normal & 605 & $86(14.2)$ & $519(85.8)$ & $1.0(0.4-2.5)$ & 0.962 \\
\hline Overweight & 320 & $45(14.1)$ & $275(85.9)$ & $1.0(0.4-2.5)$ & 0.985 \\
\hline Obese & 149 & $22(14.8)$ & $127(85.2)$ & $1.1(0.4-2.8)$ & 0.895 \\
\hline \multicolumn{6}{|l|}{ Parity: } \\
\hline $1-3$ & 967 & $123(12.7)$ & $844(87.3)$ & $0.5(0.3-0.7)$ & $<0.001$ \\
\hline $\begin{array}{l}\text { More than } 3 \\
\text { Known HIV status } \\
(n=1114)\end{array}$ & 150 & $36(24.0)$ & $114(76.0)$ & 1.0 & \\
\hline Positive & 29 & $6(20.7)$ & $23(79.3)$ & & \\
\hline Negative & 1085 & $151(13.9)$ & $934(86.1)$ & $1.6(0.6-4.0)$ & 0.301 \\
\hline \multicolumn{6}{|c|}{ Alcohol consumption: } \\
\hline Yes & 208 & $30(14.4)$ & $178(85.6)$ & 1.0 & \\
\hline No & 909 & $129(14.2)$ & $780(85.8)$ & $1.0(0.7-1.6)$ & 0.931 \\
\hline
\end{tabular}


Adverse maternal outcomes and their associations with PD are summarized in Table 3. Postpartum women with PD at delivery had a 3.4 higher odds of pre-eclampsia than women without (OR $=3.4$; 95\% CI: 2.20-5.40). In contrast, there was no statistically significant association between PD and eclampsia, preterm premature rupture of membranes or term rupture

Table 3: Adverse maternal outcome associated with periodontal disease $(\mathrm{N}=1117)$

\begin{tabular}{|c|c|c|c|c|c|}
\hline \multirow{3}{*}{ Outcome } & \multirow{3}{*}{ Total } & \multicolumn{2}{|c|}{ Periodontal disease } & \multirow{3}{*}{ OR $(95 \% \mathrm{Cl})$} & \multirow{3}{*}{$p$-value } \\
\hline & & Present & Absent & & \\
\hline & & $\mathrm{n} \quad(\%)$ & n $(\%)$ & & \\
\hline \multicolumn{6}{|c|}{ Pre-eclampsia } \\
\hline Yes & 101 & $33(32.7)$ & $68(67.3)$ & & \\
\hline No & 1016 & $126(12.4)$ & $890(87.6)$ & $3.4(2.2-5.4)$ & $<0.001$ \\
\hline \multicolumn{6}{|l|}{ Eclampsia } \\
\hline Yes & 16 & $5(31.2)$ & $11(68.8)$ & & \\
\hline No & 1101 & $154(14.0)$ & 947 (86.0) & $2.8(1.0-8.2)$ & 0.050 \\
\hline \multicolumn{6}{|c|}{$\begin{array}{l}\text { Severity of pre- } \\
\text { eclampsia }(n=101) \text { : }\end{array}$} \\
\hline Mild & 39 & $9(23.1)$ & $30(76.9)$ & & \\
\hline Severe & 62 & $24(38.7)$ & $38(61.3)$ & $0.5(0.2-1.2)$ & 0.103 \\
\hline \multicolumn{6}{|c|}{$\begin{array}{l}\text { Pre-term premature } \\
\text { rupture of } \\
\text { membranes }(n=110) \text { : }\end{array}$} \\
\hline Yes & 26 & $9(34.6)$ & $17(65.4)$ & & \\
\hline No & 84 & $22(26.2)$ & $62(73.8)$ & $1.5(0.6-3.8)$ & 0.404 \\
\hline
\end{tabular}

Adverse fetal outcomes and their association with PD are summarized in Table 4. Women shown to have had PD at delivery had a 2.6 higher odds of delivering children with LBW $(<2.5 \mathrm{~kg})$ than women without PD $(\mathrm{OR}=2.6$; 95\% CI: 1.70-4.00). When gestation age at delivery was analysed, mothers with PD were significantly (2.7 times) more likely to deliver before term ( $<37$ weeks gestation) than mothers without PD (OR $=2.7 ; 95 \% \mathrm{CI}: 1.70-4.20)$. Crude analysis for the main variables was performed using logistic regression with cut off points for maternal/ neonatal characteristics, and the significant associations were entered in the final model (Table 5).

Table 4: Adverse fetal outcome associated with periodontal disease $(\mathrm{N}=1117)$

\begin{tabular}{|c|c|c|c|c|c|}
\hline \multirow{3}{*}{ Outcomes } & \multirow{3}{*}{ Total } & \multicolumn{2}{|c|}{ Periodontal disease } & \multirow{3}{*}{ OR $(95 \% \mathrm{Cl})$} & \multirow{3}{*}{$p$-value } \\
\hline & & \multirow{2}{*}{$\begin{array}{l}\text { Present } \\
\mathrm{n} \quad(\%)\end{array}$} & Absent & & \\
\hline & & & n $(\%)$ & & \\
\hline \multicolumn{6}{|l|}{$\begin{array}{l}\text { Gestational age } \\
\text { at delivery } \\
\text { (weeks): }\end{array}$} \\
\hline Term/ postdate & 1007 & $128(12.7)$ & $879(87.3)$ & & \\
\hline $\begin{array}{l}\text { Preterm } \\
\text { Birth-weight } \\
\text { (kg): }\end{array}$ & 110 & $31(28.2)$ & 79 (71.8) & $2.7(1.7-4.2)$ & $<0.001$ \\
\hline Mean (SD) & 1117 & $2.9(0.7)$ & $3.1(0.6)$ & $-0.2[(-0.3-(-0.1)]$ & $<0.001$ \\
\hline Normal & 941 & $122(13.0)$ & $819(87.0)$ & 1.0 & \\
\hline Low birthweight & 123 & $34(27.6)$ & $89(72.4)$ & $2.6(1.7-4.0)$ & $<0.001$ \\
\hline Overweight & 53 & $3(5.7)$ & 50 (94.3) & $0.4(0.1-1.3)$ & $0.138^{*}$ \\
\hline
\end{tabular}

*=Fisher Exact $p$-value 
Table 5: Adjusted odds ratio of maternal and neonatal characteristics

and presence of periodontal disease $(\mathrm{N}=1117)$

\begin{tabular}{lll} 
VARIABLE & ${ }_{\mathrm{COR}}(95 \% \mathrm{Cl})$ & ${ }_{\mathrm{A}} \mathrm{OR}(95 \% \mathrm{Cl})$ \\
\hline Pre-eclampsia at delivery $^{1,2}$ & $3.43(2.23-5.41)$ & $4.12(2.20-7.90)$ \\
Preterm premature rupture of membranes $^{1,2}$ & $2.62(1.45-5.01)$ & $1.83(0.75-4.21)$ \\
Eclampsia $^{1,2}$ & $2.85(1.05-8.25)$ & $3.71(0.80-17.13)$ \\
Low birthweight $(<2500 \mathrm{~g})^{1,2,3}$ & $2.69(1.74-4.27)$ & $2.41(1.34-4.33)$ \\
Pre-term birth (gestation age $<37$ weeks) $^{1,2,4}$ & $2.69(1.71-4.25)$ & $2.32(1.33-4.27)$ \\
\hline
\end{tabular}

\footnotetext{
COR: Crude Odds Ratio; ${ }_{\mathrm{A}} \mathrm{OR}$ : Adjusted Odds Ratio; (95\% Cl): 95\% Confidence Interval;

1 : adjusted for age, parity

2 : adjusted for the same adverse fetal outcome

3 : adjusted for previous low birth weight and pre-eclampsia

${ }^{4}$ : adjusted for previous preterm birth and pre-eclampsia
}

As regards the relationship between PD and adverse maternal outcomes PE/eclampsia and pPROM, after adjustment for age, parity, and previous history of these events the association with PE was significantly higher in women with PD adjusted Odds Ratio 95\% Confidence Interval (aOR $=4.12 ; 95 \% \mathrm{CI}: 2.20-7.90)$, but it was not statistically significant for pPROM and eclampsia which presented aORs of 1.83; 95\% CI: 0.75-4.21) and (3.71; 95\% CI: 0.80-17.13)respectively. As for the association between PD and adverse fetal outcomes, after adjustment for age, parity, and previous history the aORs were (2.41; 95\% CI: 1.34-4.33) for LBW and (2.32; 95\% CI: 1.334.27) for PTB and were statistically significant in both cases.

\section{Discussion}

Periodontal disease has been associated with certain adverse pregnancy outcomes such as LBW, PTB, pPROM and PE. Our principal findings indicate that maternal periodontal disease is a potential independent risk indicator for pre-eclampsia, low birth weight and preterm birth. Modelled estimates for Tanzania suggest that 23\% of newborn deaths are due to complications of PTB. Eightysix per cent of newborn deaths are also LBW, many of which are $\mathrm{PTB}^{22}$. Maternal systemic infections can elicit an inflammatory response that results in inflammation of the maternal-fetal-placental unit including the uterus, chorioamniotic membranes, placenta, amniotic fluid, fetal lungs and circulation. These inflammatory stimuli in- duce hyper-irritability of the smooth muscle of the uterus, enhancing contractility, cervical thinning and cervical dilatation, and may thus trigger preterm labour ${ }^{4,23,24}$. For its part, maternal periodontal disease can adversely affect pregnancy by causing bacteria and inflammatory mediators to spread from the oral cavity to the fetal placental unit via the blood. ${ }^{1}$

In Tanzania, there is no epidemiological data regarding periodontal disease in pregnant women. One of the strengths of our study is the sample size: more than 1100 pregnant women were included, of whom $14.2 \%$ presented with periodontal disease. The prevalence was strongly influenced by older age and parity above 3 . These results are in agreement with a study in Brazil which found a prevalence of $11 \%{ }^{25}$, but other authors have reported higher rates of PD among pregnant women ${ }^{3,12,26,27}$.

The associations found in our study between lower rates of PD, age under 35 and parity of $1-3$ are probably due to the higher levels of education in the younger population and the study setting. Our study was carried out at a tertiary teaching hospital in an area where most of the community lives in an urban setting, a fact which may have influenced the results of the study: well-educated individuals in urban environments are likely to have a better understanding of the need for good oral hygiene and have a lower risk of developing periodontal disease. Other studies have associated the prevalence of periodontal disease with low educational level, residence in rural en- 
vironments, poor oral hygiene and cigarette smoking ${ }^{8,28}$. Cigarette smoking is not a common habit among Tanzanian women and indeed none of our population were smokers.

The prevalence of PD varies depending on the population investigated and the definition and the recording index used. One of the weaknesses of most studies is the inconsistency in the recording of prevalence and severity of PD, a drawback that influences the results and limits the possibility of making valid comparisons between studies. In this study the CPI scoring system was the method used for measuring periodontal status ${ }^{29}$.

This study found a significant association between PD and PE [aOR 4.12 (95\% CI: 2.20-7.90)] indicating that PD may influence adverse pregnancy outcomes in Northern Tanzania. Parity more than 3, age 36 - 45 and history of previous $\mathrm{PE}$ were strongly associated with development of $\mathrm{PE}$ in women with $\mathrm{PD}$, in agreement with previous reports in the $\mathrm{US}^{30}, \operatorname{Iran}^{31}$, Italy ${ }^{32}$, and Brazil ${ }^{33}$ which found significant associations between pre-eclampsia and PD. In a meta-analysis including 13 observational case control studies and two cohort studies, Wei and colleagues also found a significant association between PD and pre-eclampsia ${ }^{34}$.

However, studies conducted by Nabet et al. ${ }^{3}$ and Pattanashetti et al. ${ }^{35}$ found a strong association between PD and induced PTB due to preeclampsia. Our findings are at odds with those of studies performed in Iran and Italy by Abati et al. ${ }^{1}$ and Yaghini et al. ${ }^{36}$, who did not report this association.

Certain similarities have been reported between preeclampsia and atherosclerosis. Like preeclampsia, atherosclerosis is associated with endothelial dysfunction, which may be caused by oxidative stress and subsequent lipid peroxidation, hyperlipidemia or homocysteinemia ${ }^{37}$. Epidemiological factors such as obesity, history of hypertension and African ancestry render the person susceptible to pre-eclampsia and atherosclerosis. One of the reasons for abnormalities in endothelial function is the presence of severe inflammatory responses. Periodontal disease, a chronic oral Gram-negative infection, has been associated with atherosclerosis, thromboembolic events and hypercholesterinemia. Oral pathogens have been detected in atherosclerotic plaque where they may play a role in the development and progression of atherosclerosis, leading to coronary vascular disease. Periodontal disease may cause a chronic burden of endotoxin and inflammatory cytokines which serve to initiate and exacerbate athrogenesis and thrombogenesis. It is possible that the placenta may be similarly burdened in pregnant women who develop pre-eclampsia ${ }^{37,38,39}$. Women with active periodontal disease during pregnancy may have transient translocation of oral organisms to the uteroplacental unit, causing placental inflammation or oxidative stress early in pregnancy which ultimately produces placental damage and the clinical manifestation of pre-eclampsia. Studying umbilical cord serum, Madianos et al assessed the presence of fetal immunoglobulin $\mathrm{M}$ against oral pathogens, and identified the production of fetal IgM against Porphyromonas gingivalis; this finding indicates a fetal humoral response to organisms distant from the intrauterine environment and suggests the possibility of translocation of oral pathogens to the uteroplacental unit ${ }^{14}$. Other authors have detected a molecular increase of oral bacteria such as Fusobacterium nucleatum in the placenta tissues of pregnant periodontitis patients ${ }^{40}$.

PTB or LBW newborns are a major cause of infant mortality and morbidity, and those who survive suffer a higher risk of developing neurodevelopmental, respiratory, cardiovascular and metabolic abnormalities as well as learning disabilities. It is clear that the causes of PTB and LBW are complex and multifactorial, but the mechanisms involved may present common pathways. Infection is an important risk factor for preterm low birth weight and so periodontal disease may be linked to this process ${ }^{41}$. Due to the high morbidity and mortality rates, PTB represents a significant public health problem in Tanzania, which is among the countries with the highest perinatal and child mortality indices ${ }^{22}$.

This study also found associations between PD and PTB and LBW. After adjusting for participant's age, parity, presence of pre-eclampsia and history of previous LBW and PTB, the relationship was statistically significant in all cases. These findings corroborate those of studies elsewhere in Africa and in other parts of the world, which have recorded significant associations between PD, PTB and $\mathrm{LBW}^{26,42-47}$. However, two studies conducted in Ita$1 y^{1,48}$ and one in Taiwan $^{49}$ found no association between PTB and PD, and an earlier study in Tanzania conducted 
by Mumghamba and Manji ${ }^{50}$ failed to demonstrate the association between PD and preterm LBW.

Our study did not find a significant statistical association between PD and PPROM or eclampsia, even though the findings were clinically significant. Similarly, Abati et al. in Italy found no association between PD and adverse pregnancy outcomes including PPROM $^{1}$.

Future studies should aim to identify possible correlations between the maternal subgingival microbiota and the placental microbioma, and analyse common inflammatory factors at both these sites. In any case, new policies are needed to provide systematic periodontal treatment for all pregnant patients with periodontal disease and thus control one of the main risk factors for adverse pregnancy outcomes.

\section{Conclusion}

In summary, maternal periodontal disease is a potential independent risk indicator for pre-eclampsia, low birth weight and preterm birth. Periodontal examination and treatment for women with pre-existing periodontal disease can reduce the risk of recurrence or deterioration, and should form part of the preventive antenatal care provided in developing countries. Taken together with other studies, our findings suggest that the disparate results regarding the association between periodontal disease and adverse outcomes are partly due to the definitions used and the populations studied.

\section{Ethical consideration}

Ethical clearance certificate No. 822 was obtained from the Kilimanjaro Christian Medical University College Research and Ethics Committee. Study participants signed an informed consent form before data collection and all the information was treated confidentially. Participants who did not provide consent received the same care as those who did.

\section{Acknowledgements}

Clínics Associates, a well-established Professional Partnership in Terrassa (Barcelona), deserves a special mention for leading and supporting KiliBarnaDental project at Soweto General Hospital in Arusha, United Republic of Tanzania, East Africa. The authors thank Ombeni Mrina, dental therapist, for his excellent assistance.

\section{Conflict of interest}

The authors declare that they have no conflict of interest.

\section{Funding information}

The study was self- funded by the authors.

\section{References}

1. Abati S, Villa A, Cetin I, Dessole S, Lugliè PF, Strohmenger L, et al. Lack of association between maternal periodontal status and adverse pregnancy outcomes: a multicentric epidemiologic study. J Matern Fetal Neonatal Med. 2013; 26 (4): 369-372. DOI:10.3109/14767058.201 2.733776 .

2. Periodontal Disease Fact Sheet. American Academy of Periodontology - Perio.org. IL. Chicago 2017. https://www.perio.org/newsroom/periodontal-disease-fact-sheet (Last accessed Feb 2017).

3. Nabet C, Lelong N, Colombier M-L, Sixou M, Musset A-M, Goffinet F, et al. Maternal periodontitis and the causes of preterm birth: the case-control Epipap study. J Clin Periodontol. 2010; 37 (1):37-45. DOI:10.1111/j.1600051X.2009.01503.x.

4. Offenbacher S, Lieff S, Boggess KA, Murtha AP, Madianos PN, Champagne CM, et al. Maternal periodontitis and prematurity. Part I: Obstetric outcome of prematurity and growth restriction. Ann Periodontol, 2001; 6 (1): 164-174. DOI:10.1902/annals.2001.6.1.164. PubMed .

5. Xiong X, Buekens P, Vastardis S, Yu SM. Periodontal disease and pregnancy outcomes: state-of-the-science. $O b$ stet Gynecol Surv. 2007; 62 (9): 605-615. DOI:10.1097/01. ogx.0000279292.63435.40.

6. World Bank Country and Lending Groups. The World Bank Group - worldbank.org. 2017 https://datahelpdesk.worldbank.org/knowledgebase/articles/906519world-bank-country-and-lending-groups (Last accessed Nov 2017).

7. Kassebaum NJ, Bernabé E, Dahiya M, Bhandari B, Murray CJ, Marcenes W. Global burden of severe periodontitis in 1990-2010: a systematic review and meta-regression. J Dent Res. 2014; 93(11): 1045-1053. PubMed. DOI:10.1177/0022034514552491.

8. Wandera M, Astrøm AN, Okullo I, Tumwine JK. Determinants of periodontal health in pregnant women and association with infants' anthropometric status: aprospective cohort study from Eastern Uganda. BMC Pregnancy Childbirth. 2012; 12: 90. DOI:10.1186/1471-2393-12-90. 
9. Offenbacher S, Katz V, Fertik G, Collins J, Boyd D, Maynor $\mathrm{G}$, et al. Periodontal infection as a possible risk factor for preterm low birth weight. J Periodontol. 1996; 67 (10 Suppl): 1103-1113. DOI:10.1902/jop.1996.67.10s.1103. 10. Manji KP, Massawe AW, Mgone JM. Birthweight and neonatal outcome at the Muhimbili Medical Centre, Dar es Salaam, Tanzania. East Afr Med J. 1998; 75 (7): 382387. PMID:9803627.

11. Dasanayake AP. Poor periodontal health of the pregnant woman as a risk factor for low birth weight. Ann Periodontol. 1998; 3 (1): 206-212. DOI:10.1902/annals.1998.3.1.206. PubMed .

12. Kim J, Amar S. Periodontal disease and systemic conditions: a bidirectional relationship. Odontology. 2006; 94 (1): 10-21. DOI:10.1007/s10266-006-0060-6.

13. Williams CE, Davenport ES, Sterne JA, Sivapathasundaram V, Fearne JM, Curtis MA. Mechanisms of risk in preterm low-birthweight infants. Periodontol. 2000 2000; 23: 142-150. PMID:11276762.

14. Madianos PN, Bobetsis YA, Offenbacher S. Adverse pregnancy outcomes (APOs) and periodontal disease: pathogenic mechanisms. J Periodontol, 2013; 84 (4 Suppl): S170-180. DOI:10.1902/jop.2013.1340015.

15. Wardlaw T, Blanc A, Zupan J, Åhman E. (2004) Low Birth Weight: country, regional and global estimates, World Health Organization \& UNICEF.NewYork. https://www.unicef.org/publications/files/low_birthweight_from_EY.pdf (Last Accessed Feb 2017).

16. Horton AL, Boggess KA. Periodontal disease and preterm birth. Obs Gyne-col Clin North Am. 2012; 39 (1): 17-23. DOI:10.1016/j.ogc.2011.12.008.

17. Ainamo J, Barmes D, Beagrie G, Cutress T, Martin J. Development of the world health organization (WHO) community periodontal index of treatment needs (CPITN). Int Dent J. 1982; 32 (3): 281-291. PMID:6958657.

18. Cutress TW, Ainamo J, Sardo-Infirri J. The community periodontal index of treatment needs (CPITN) procedure for population groups and individuals. Int Dent J. 1987; 37: 222-233. PMID:3481626.

19. Gomes-Filho IS, Cruz SS, Rezende EJ, Dos Santos CA, Soledade KR, Magalhães MA, et al. Exposure measurement in the association between periodontal disease and prematurity/low birth weight. J Clin Periodontol. 2007; 34 (11): 957-963. PubMed. DOI:10.1111/j.1600051X.2007.01141.x.

20. Miller PD. A classification of marginal tissue reces- sion. Int J Periodontics Restorative Dent. 1985; 5 (2): 8-13. PMID:3858267.

21. Miranda J, Brunet L, Roset P, Farré M, Mendieta C. Reliability of two measurement indices for gingival enlargement. J Periodontal Res. 2012; 47 (6): 776-782. DOI:10.1111/j.1600-0765.2012.01495.x.

22. The National Road Map Strategic Plan To Accelerate Reduction of Maternal, Newborn and Child Deaths in Tanzania 2008-2015. United Republic of Tanzania Ministry of Health and Social Welfare. Sharpened One Plan. 2014.

23. Berkowitz K, LaSala A. Risk factors associated with the increasing prevalence of pneumonia during pregnancy. Am J Obstet Gynecol. 1990; 163 (3): 981-985. PMID:2403178.

24. Romero R, Mazor M, Munoz H, Gomez R, Galasso M, Sherer DM. The preterm labor syndrome. Ann N Y Acad Sci. 1994; 734: 414-429. PMID:7978942.

25. Piscoya MD, Ximenes RA, Silva GM, Jamelli SR, Coutinho SB. Maternal periodontitis as a risk factor for prematurity. Pediatr Int, 2012; 54 (1): 68-75. DOI:10.1111/ j.1442-200X.2011.03502.x.

26. Martinez de Tejada B, Gayet-Ageron A, Combescure C, Irion O, Baehni P. Association between early preterm birth and periodontitis according to USA and European consensus definitions. J Matern Fetal Neonatal Med. [Internet].2012; 25 (11): 2160-2166. PubMed. DOI:10.3109/1 4767058.2012 .663827$.

27. Armitage GC. Periodontal diagnoses and classification of periodontal diseases. Periodontol. 2000 2004; 34: 9-21. PMID:14717852

28. Vogt M, Sallum AW, Cecatti JG, Morais SS. Periodontal disease and some adverse perinatal outcomes in a cohort of low risk pregnant women. Reprod Health. 2010; 7 (1): 29. DOI:10.1186/1742-4755-7-29.

29. Ide M, Papapanou PN. Epidemiology of association between maternal periodontal disease and adverse pregnancy outcomes - systematic review. J Periodontol. 2013; 84 (4 Suppl S1): 81-94. DOI:10.1902/jop.2013.134009. 30. BoggessKA, Lieff S, Murtha AP, Moss K, Beck J, Offenbacher S. Maternal periodontal disease is associated with an increased risk for pre-eclampsia. Obstet Gynecol. 2003;101 (2): 227-231. PMID:12576243.

31. Sayar F, Hoseini MS, Abbaspour S. Effect of periodontal disease on pre-eclampsia. Iran J Public Health, 2011; 40 (3): 122-127. PMID:23113094.

32. Sgolastra F, Petrucci A, Severino M, Gatto R, Mo- 
naco A. Relationship between periodontitis and pre-eclampsia: a meta-analysis. PLoS One, 2013; 8 (8): e71387. DOI:10.1371/journal.pone.0071387. eCollection 2013.

33. Moura da Silva G, Coutinho SB, Piscoya MD, Ximenes RA, Jamelli SR. Periodontitis as a risk factor for preeclampsia. J Periodontol. 2012; 83 (11): 1388-1396. DOI:10.1902/jop.2012.110256.

34. Wei BJ, Chen YJ, Yu L, Wu B.Periodontal disease and risk of pre-eclampsia: a meta-analysis of observational studies. PLoS One. 2013; 8 (8): e70901.DOI:10.1371/ journal.pone.0070901. eCollection 2013.

35. Pattanashetti JI, Nagathan VM, Rao SM. Evaluation of periodontitis as a risk for preterm birth among preeclamptic and non-pre-eclamptic pregnant women - a case control study. J Clin Diagn Res. 2013; 7 (8): 17761778. DOI:10.7860/JCDR/2013/6497.3308.

36. Yaghini J, Mostajeran F, Afshari E, Naghsh N. Is periodontal disease related to pre-eclampsia? Dent Res J. (Isfahan) 2012; 9(6): 770-773.PMID:23559957.

37. Jia R, Kurita-Ochiai T, Oguchi S, Yamamoto M. Periodontal pathogen accelerates lipid peroxidation and atherosclerosis. J Dent Res. 2013; 92 (3): 247-252. DOI:10.1177/0022034513475625.

38. Khashan AS, Kenny LC. The effects of maternal body mass index on pregnancy outcome. Eur J Epidemiol. 2009; 24 (11): 697-705. DOI:10.1007/s10654-009-9375-2.

39. ZelkhaSA, Freilich RW, Amar S. Periodontal innate immune mechanisms relevant to atherosclerosis and obesity. Periodontol. 2000 2010; 54 (1): 207-221. DOI:10.1111/ j.1600-0757.2010.00358.x.

40. Blanc V, O’Valle F, Pozo E, Puertas A, León R, Mesa F. Oral bacteria in placental tissues: increased molecular detection in pregnant periodontitis patients. Oral Dis. 2015; 21 (7): 905-912. DOI:10.1111/odi.12364.

41. Vergnes J-N, Sixou M. Preterm low birth weight and maternal periodontal status: a meta-analysis. $A m \mathrm{~J}$ Obstet Gynecol. 2007; 196 (2) 135: e1-7.DOI:10.1016/j. ajog.2006.09.028.

42. Jacob PS, Nath S. Periodontitis among poor rural Indi- an mothers increases the risk of low birth weight babies: a hospital-based case control study. J Periodontal Implant Sci. 2014; 44 (2): 85-93. DOI:10.5051/jpis.2014.44.2.85 PubMed.

43. Haerian-ArdakaniA, Eslami Z, Rashidi-Meibodi F, Haerian A, Dallalnejad P, Shekari M, et al. Relationship between maternal periodontal disease and low birth weight babies. Iran J Reprod Med. 2013; 11 (8): 625-630. PMID:24639799

44. Corbella S, Taschieri S, Francetti L, De Siena F, Del Fabbro M. Periodontal disease as a risk factor for adverse pregnancy outcomes: a systemic review and meta-analysis of case-control studies. Odontology. 2012; 100 (2): 232-240. DOI:10.1007/s10266-011-0036-z.

45. Mannem S, Chava VK. The relationship between maternal periodontitis and preterm low birth weight: A case-control study. Contemp Clin Dent. 2011; 2 (2): 88-93. DOI:10.4103/0976-237X.83067.

46. Baskaradoss JK, Geevarghese A, Kutty VR. Maternal periodontal status and preterm delivery: a hospital based case-control study. J Periodontal Res. 2011; 46 (5): 542-549. DOI:10.1111/j.1600-0765.2011.01371.x.

47. Muwazi L, Rwenyonyi CM, Nkamba M, Kutesa A, Kagawa M, Mugyenyi G, et al. Periodontal conditions, low birth weight and preterm birth among postpartum mothers in two tertiary health facilities in Uganda. BMC Oral Health. 2014; 14: 42. DOI:10.1186/1472-6831-14-42. 48. Calabrese N, Calabrese A, Nibali L, Rosati A, Fiengo S, Di Renzo GC. Is there any association between periodontitis and preterm low birth weight? J Matern Fetal Neonatal Med. 2010; 23 (11): 1288-1293. DOI:10.3109/14767051003615467.

49. Wang YL, Liou JD, Pan WL. Association between maternal periodontal disease and preterm delivery and low birth weight. Taiwan J Obstet Gynecol. 2013; 52 (1): 71-76. DOI: 10.1016/j.tjog.2013.01.011.

50. Mumghamba EGS, Manji KP. Maternal oral health status and preterm low birth weight at Muhimbili National Hospital, Tanzania: a case-control study. BMC Oral Health 2007; Jun 26 (7):8. DOI:10.1186/1472-6831-7-8. 